\title{
Severely threatening events and marked life difficulties preceding onset or exacerbation of multiple sclerosis
}

\author{
IGOR GRANT,* GEORGE W BROWN, $\dagger$ TIRRIL HARRIS, $\dagger$ W IAN MCDONALD, $\ddagger$ \\ THOMAS PATTERSON, * MICHAEL R TRIMBLE \\ From the San Diego V.A. Medical Center and Department of Psychiatry, University of California (San Diego) \\ School of Medicine, La Jolla, USA, ${ }^{*}$ Bedford and Royal Holloway Colleges, University of London, $\dagger$ and Institute \\ of Neurology, National Hospitals, Queen Square and Maida Vale, $\ddagger$ London, UK
}

SUMMARY Information was obtained on stressful life circumstances, using the Life Events and Difficulties Schedule (LEDS) from 39 patients with early multiple sclerosis and 40 matched nonpatient volunteers. The proportion of multiple sclerosis patients who experienced marked life adversity in the year prior to onset of symptoms was significantly higher than for nonpatients in the year before interview (77\% vs. 35\%). The excess in marked life stress was most evident in the 6 months before onset. Such stressors might explain the timing of symptom exacerbation for some patients with multiple sclerosis, perhaps by perturbing an already unstable neuroimmunological system.

There has been speculation that stressful life circumstances can influence onset and exacerbation of symptoms of multiple sclerosis virtually from the time the disease was first described in the middle of the last century. The biography of Augustus d'Este raises the question whether emotional arousal over the death of a close relative might have been related to the abrupt beginning of his ophthalmological symptoms. ${ }^{1}$ In 1868 Charcot, who first delineated multiple sclerosis as we know it today, commented that grief, worry, and adverse changes in social circumstances might be causally linked to disease onset, ${ }^{2}$ and Moxon's 1873 case report notes a possible association between disease onset and his patient's having discovered her husband in bed with another woman. ${ }^{3}$

Several American studies, influenced by psychoanalytic theory, suggested that stress could produce cerebrovascular alterations which might be aetiologically related to plaque formation. ${ }^{4}$ Others asserted that patients with multiple sclerosis had neurotic conflicts between dominance and submission which expressed themselves as neurological symptoms, ${ }^{j-7}$ or that such patients could develop the disorder in the context of protracted emotional arousal, ${ }^{8}$. particularly anger,' or circumstances which posed a threat to the patient's "security system". ${ }^{10}$

Address for reprint requests: Professor I. Grant, Psychiatry Service (116), V.A. Medical Center, San Diego, CA 92161 USA

Received 8 March 1988 and in revised form 15 July 1988. Accepted 21 July 1988
Engel and associates believed that patients who were 0 vulnerable to multiple sclerosis developed it when their life circumstances caused emotional conflict resulting in the "giving up-given up complex"."

Provocative as these studies were, their lack of comparison groups left their speculations open to serious question. The first controlled study appears to have been that of Pratt. ${ }^{12}$ While noting certain individual patients in whom emotional upheavals seemed to precede exacerbation of symptoms, Pratt did not find a statistically significant difference between multiple sclerosis patients and a non-multiple sclerosis neurological comparison group in their experience of life events. Another large controlled study found that multiple sclerosis patients tended to report more serious interpersonal difficulties prior to onset than did controls, but the magnitude of the difference $(19 \%$ of multiple sclerosis patients as compared with $12 \%$ of controls) left the practical importance of this finding open to question. ${ }^{13}$

Two controlled studies which were reported in the 1980s found significant associations between life events and multiple sclerosis symptomatology. The first compared 100 multiple sclerosis patients with 73 neurological and rheumatological patients. ${ }^{14}$ In the two years prior to onset of disease multiple sclerosis patients reported three times as many life events; furthermore, more of the multiple sclerosis patients considered themselves to be subjected to unusual stresses during that period $(79 \%$ of multiple sclerosis vs. $54 \%$ of controls). 
The Denver group of investigators gathered data on life events every 4 months for an average of 20 months from 55 patients with relapsing-remitting multiple sclerosis. ${ }^{15}$ Patients who reported significant negative or uncontrollable events were $\mathbf{3 . 7}$ times as likely to have an exacerbation as those free of such events.

In sum, despite a wealth of anecdotal evidence suggesting an association between life stresses and multiple sclerosis exacerbation, the results of controlled studies have been distinctly mixed. We report on a cohort of multiple sclerosis patients examined at the National Hospital, Queen Square, and compare the experiences of our patients with those of matched nonpatients using an improved life events methodology (the Bedford College Life Events and Difficulties Schedule (LEDS)) a technique which has been applied successfully in research into other disorders but not, until the present time, with multiple sclerosis.

\section{Method}

\section{Subjects}

A Multiple sclerosis group $(N=39)$ These patients were recent referrals to consultant neurologists at the National Hospitals, Queen Square, and Maida Vale. The median time between symptom onset and entry into the study was two years with a range of 1 to 54 months. Thirty-three of these patients also participated in a related neuropsychological study of deficient learning and memory in early multiple sclerosis the results of which have already been reported.16

There were 10 men and 29 women (originally there were 30 women, but one was excluded because the diagnosis of probable multiple sclerosis turned out to be incorrect), whose average age was $35 \cdot 6$, SD 9.0. Most (85\%) were middle class as defined by points 1-22 on the Hope-Goldthorpe scale. ${ }^{17}$ Of these 39 patients 32 were married and 27 had children. At the time patients were recruited the diagnostic requirement was that patients must qualify either for probable or definite multiple sclerosis. At the time of this writing, however, all "probable" patients have had further neurological assessment and all now qualify as definite multiple sclerosis either on clinical grounds or based on laboratory-supported data..$^{18}$ At the time of examination 25 of the patients were undergoing diagnostic evaluations as inpatients, and the remaining 14 attended as outpatients. The mean disability score, based on the Kurtzke Expanded Disability Status Scale was 2.2 (range 1.0-6.5) at time of interview. Although virtually all patients experienced some transient symptoms previously, 23 had their first medically documented episode at the time of this study, while the remaining 16 had relapses. At time of interview 16 patients knew their diagnosis while 23 did not.

B Healthy comparison group $(N=40)$ Because the authors were engaged in concurrent epidemiological studies of healthy volunteers using the same measures it was possible to recruit non-patients, matched on a case by case basis for age, sex, marital status, and socioeconomic position to the multiple sclerosis patients (we have one more control than patient because a patient had to be dropped-see above). The non-patient group consisted of 10 men and 30 women of whom 28 were married, 23 had children, and whose mean age was $35 \cdot 7$, SD 9.7. Based on a rating of 1-22 on the HopeGoldthorpe scale, $80 \%$ of this group was middle class.

\section{Life Events Interviews}

Three of the four controlled studies reviewed above may have suffered from methodological inadequacies in the gathering of life events information, and these inadequacies could, in part, explain disparate results. One of the studies ${ }^{14}$ obtained information on the basis of a self-report check list whose validity increasingly is subject to question. ${ }^{19-21}$ The other two performed interviews, but these were idiosyncratic to the specific projects, hence we have no data on reliability.

The Life Events and Difficulties Schedule (LEDS) developed by Brown and associates has received increasing international recognition as a valid and reliable approach for ascertaining life events, difficulties, and important sources of social support. ${ }^{19}$ For this reason, it appeared to represent an advance in the current research. The LEDS consists of a semi-structured interview which probes systematically for the occurrence of life events and difficulties in a comprehensive fashion covering many content areas. In this project the interviewers received training by the Bedford College team to assure consistency in data gathering. Each interview took approximately 2 hours to complete. In the case of multiple sclerosis patients data on life circumstances were gathered for the year preceding onset of major symptoms. For nonpatients, the interview concentrated on information in the year preceding interview. This means that patients were reporting on events which occurred 2 to 3 years prior to the interview while non-patients were recollecting the past year. While this difference in recall length between patients and controls is not ideal, the literature suggests that, if anything, number of events recalled tends to drop off with length of recall period. ${ }^{2}$ Thus, bias in this study would be in the direction against our hypothesis, reducing the number of events reported by patients, and increasing those reported by controls.

\section{Analysis of LEDS information}

Information on life circumstances obtained from the LEDS was grouped into two categories: events; and difficulties. Events were happenings occurring at relatively discrete points in time, while difficulties represented life circumstances which went on for 4 weeks or more. Difficulties might commence with a discrete event or might develop more insidiously.

A commonly acknowledged limitation in life events research comes from the appreciation that people can vary widely as to the subjective "stressfulness" rating which they might attach to a particular happening. For this reason, Brown and Harris ${ }^{1923}$ have argued that it is important to supplement subjective ratings with contextual ratings.

\section{Contextual Ratings}

Contextual ratings are performed by the research team after it has heard a precis of a particular subject's situation, life events, and difficulties. Using a set of decision rules that have evolved as part of the LEDS instrument, and by frequent reference to an extensive dictionary of events and difficulties 
which have been gathered over several thousand interviews, the investigators can make a judgement as to whether a reported happening should be considered a true event or difficulty (rather than simply a trivial incident, of insufficient importance to include in data analysis), and, if so, what ratings to give to relevant dimensions such as independence, focus, and threat. The threshold for including incidents in data analysis was deliberately set high in terms of their likelihood of arousing a strong positive or negative emotion. ${ }^{25}$ Some examples of events which might have been counted in earlier studies, but which were eliminated by our threshold are: patient's husband gives notice to his employer that he is quitting his job, something which the family has planned; death of a patient's grandmother abroad (patient had not seen the grandmother for many years); a patient's son applying to University; a patient's sister having a planned abortion.

\section{Ratings of Events}

Once an event was included in data analysis, the investigators rated the degree of "threat" it posed to the person's security, relationships, future, or some other important aspect of his life. A 4-point scale was used, with level 1 indicating a very severe threat, level 2 moderately severe, level 3 moderate to mild, level 4 mild to minimal. The probable duration of threat was also rated as short-term if it was concluded that the major impact of the event had dissipated within $\mathbf{4 8}$ hours, or longterm if the probable effect was going to be more long-lasting. An example with high short-term threat but little long-term threat would be a parent receiving news that a child was involved in a road accident and was now at a casualty department (threat level $=1$, short-term); when the parents arrive at casualty they discover that the child is perfectly fine, simply having a few scratches (long-term threat $=4$ ). On the other hand, if the same parents discover that the child had indeed suffered a cerebral hemorrhage, then the long-term threat would remain severe (level 1). A further variation on the same event might be that the parents were told by the school that their child suffered a minor knock on the head while playing football and seemed perfectly fine (short-term threat $=3$ ); within the next two days the child developed severe headaches, became unconscious, and was found to have an intracranial bleed (long-term threat $=1$ ).

Events were also rated as to focus. A rating of self-focus (identical to Brown and Harris' "subject focus") indicates that the event occurred to the subject directly, or, if it occurred to another important individual in the person's life the subject was, nevertheless, directly involved in some aspect of that happening. Examples of events which would receive self-focus include being sacked, or one's husband being sacked if that circumstance is likely to produce financial hardship on the family. On the other hand, hearing that one's mother has cancer would receive a focus rating of other unless the subject was somehow intimately involved in the diagnostic workup or immediate caring of the mother.

Events were also classified on the basis that they might conceivably be related to, or even a product of the multiple sclerosis. For example, a patient who feels unsteady and has blurred vision might have an automobile accident. It would not be appropriate to consider such an event in any causal analysis exploring the influence of events upon the disease. In the results presented, such "illness-related" events were excluded.

\section{Ratings of Difficulty Level}

Those ongoing life happenings which are more appropriately considered difficulties were also rated as to level of severity using a 6-point scale in which level 1 represented extreme, hardly tolerable circumstances, whilst diffculties of level 6 were rather minor.

Illness-related difficulties (that is, those that might be products of multiple sclerosis or some other medical problem) were not included in the data analyses described below.

\section{Severe Events and Marked Difiiculties}

Previous research has indicated that of all events, those which pose substantial long-term threat to the person directly are most likely to be associated with medical and psychiatric disorders. ${ }^{1926-28}$ For the purposes of this study, we followed the convention established by Brown and Harris ${ }^{19}$ which defined severely threatening events as those which received a contextual rating on long-term threat of level 1 , or any level 2 event which had a self focus (level 1 events could have either self or other focus).

Marked difficulties were those which received contextual severity ratings at levels 1,2 or 3 . Difficulties rated 4-6 were termed mild difficulties.

Finally, a subject was classified as experiencing a marked adversity if he or she reported either a severely threatening event and/or a marked difficulty (as defined above) during the period in question.

\section{Results}

\section{Marked Adversity}

In the 6 months preceding onset 30 of the 39 multiple sclerosis patients $(77 \%)$ experienced marked life adversity as defined above. Among nonpatients 14 of $40(35 \%)$ reported marked adversity in the 6 months preceding interview. The difference in proportions is highly significant (Chi-square $=14.08, \mathrm{p}<0.001$ ).

\section{Severely Threatening Events}

Turning to the components of marked adversity which distinguished patients from nonpatients, we found that 24 of 39 multiple sclerosis patients $(62 \%)$ reported a severely threatening event, as compared with six of 40 controls $(15 \%)($ Chi-square $=18.02, p<0.001)$. There was no specific category of event (such as health change in a significant other; social role change; finances; interpersonal; miscellaneous crises) which accounted for this disproportion. Rather, severe events were scattered throughout all of these content areas.

\section{Marked Difficulties}

Patients with multiple sclerosis also experienced more marked difficulties in the 6 months prior to onset than did the controls. In this instance, 19 of 39 patients $(49 \%)$ vs. 8 of 40 controls (20\%) experienced marked difficulties throughout the 6 months preceding onset.

Significantly more patients than controls experienced marital difficulties (19 of $39-49 \%$, vs. 4 of $40-$ 
$10 \%$; Chi-square $=9.78, \mathrm{p}<0.01$ ) and difficulties with parents or siblings ( 13 of $39-33 \%$ vs. 3 of 40 $8 \%$; Chi-square $=6.24, p<0.02$ ). Interestingly, somewhat more control subjects reported difficulties with housing (11 of $40-28 \%)$ compared with multiple sclerosis patients (three of $39-8 \%$; Chi-square = $4.58, p<0.05$ ). There were no other areas of difficulty which differentiated patients from controls.

\section{Timing of Events in the Year Preceding Onset}

Figure $(a)$ shows the proportion of multiple sclerosis patients and controls reporting a severe life event during each bi-monthly period in the year preceding onset of symptomatology (or the year preceding interview for controls). In the period 7 to 12 months before onset (interview for controls) approximately 10 to $15 \%$ of subjects in each group experienced a severely threatening event. This rate remained approximately the same for controls right up to the time of interview. In contrast, at 5 to 6 months prior to onset the proportion of multiple sclerosis patients reporting severe events increased, with more than a third experiencing such an event in the two months prior to onset.

The specificity of this finding is underscored by figure $(b)$, which shows the occurrence of non-severe

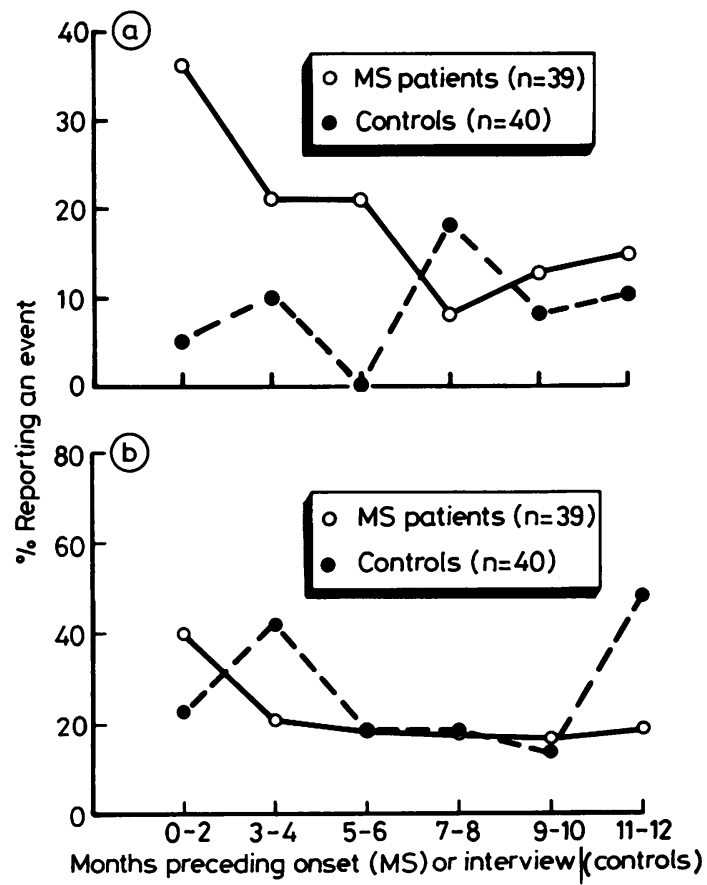

Figure Report of severely threatening life events (a) and less threating events (b) by multiple sclerosis (MS) patients and controls. events over the same 12-month period. There are no systematic differences between patients and controls in their experience of such events.

\section{Marked Adversity in Relation to Disability and Awareness of Diagnosis}

Since it is possible that environmental stress might have different importance in the precipitation of relapses versus initial episodes, we compared the distribution of marked adversity between those experiencing their first medically documented episode $(\mathbf{N}=23)$ and those with relapses $(N=16)$. Eighteen of 23 first episode cases and 12 of 16 relapsing cases reported marked adversity. Similarly, there was no significant difference in proportion of those reporting marked adversity between patients who knew versus those who were unaware of their diagnosis $(13 / 16 \mathrm{v}$ 17/23). There was no systematic association between Kurtzke Disability rating at interview and report of marked adversity. The mean Kurtzke score for those with adversity was $2 \cdot 1$ (range 1.0-6.5) and for those without adversity, $2 \cdot 3$ (range 1.0-4.0).

\section{Discussion}

In a retrospective study of patients with relatively recent onset of multiple sclerosis we found that almost three quarters of these patients experienced a marked adversity in their lives in the 6 months prior to onset of symptomatology. Only $35 \%$ of a nonpatient group matched for age, sex, marital status, and social position experienced such adversities. Multiple sclerosis patients reported more discrete events of a severely threatening nature, and also somewhat greater levels of ongoing marked life difficulties. While there were no specific classes of events which distinguished patients from controls, longstanding difficulties which seemed to occur more often among patients included concerns about spouse and blood relatives. Some of these concerns involved interpersonal conflict with these important others, while in other instances such concerns revolved around major health changes affecting such relatives.

While our results fit well with those reported from Alberta ${ }^{14}$ and Colorado, ${ }^{15}$ they are at variance with Antonovsky's ${ }^{13}$ survey of multiple sclerosis patients in Israel and also with the conclusions reached by Pratt in another British study conducted some 30 years earlier. While methodological differences could easily explain our disagreement with Antonovsky et al..$^{13}$ (they questioned their subjects concerning a limited number of life events which could have occurred as much as twenty years previously), the inconsistency with Pratt is more difficult to explain. It may be, of course, that by using a non-standard interview method Pratt might have failed to question both patients and medical 
Table 1 Examples of Classes of Marked Adversity*

\begin{tabular}{|c|c|c|}
\hline Class of Adversity & Example & $\begin{array}{l}\text { Number of } \\
\text { multiple sclerosis } \\
\text { patients reporting } \\
\text { this class of } \\
\text { adversity }\end{array}$ \\
\hline $\begin{array}{l}\text { Conflicts or prolonged separations involving spouse } \\
\text { (or lover), other close family member, or "confidant" }\end{array}$ & $\begin{array}{l}\text { Ex 1: Husband discovers patient is having affair } \\
\text { Ex 2: Chronic marital friction; couple barely } \\
\text { speaks to each other for } 9 \text { months } \\
\text { Ex 3: Son, the patient's closest "confidant", leaves the area }\end{array}$ & 19 \\
\hline $\begin{array}{l}\text { Major illness or death involving spouse (or lover), } \\
\text { other close family member, or "confidant" }\end{array}$ & $\begin{array}{l}\text { Ex 1: Patient looks after dependent son with spina bifida; } \\
\text { gets little help } \\
\text { Ex 2: Discovers illicit pregnancy of daughter } \\
\text { when it ends in abortion } \\
\text { Ex 3: Mother makes suicide attempt } \\
\text { Ex 4: Mother discovered to have cancer }\end{array}$ & 9 \\
\hline Major job-related problems & $\begin{array}{l}\text { Ex 1: Husband unexpectedly gets redundancy notice; } \\
\text { family has little money, and there is no immediate } \\
\text { prospect of another job } \\
\text { Ex 2: Patient is redeployed against her will }\end{array}$ & 5 \\
\hline $\begin{array}{l}\text { Interpersonal conflicts with neighbours, landlord, } \\
\text { acquaintances, etc . . . }\end{array}$ & $\begin{array}{l}\text { Ex 1: neighbours have frequent noisy and boisterous } \\
\text { drinking parties-frequent confrontations to point } \\
\text { patient decides on moving } \\
\text { Ex 2: Co-worker tries to seduce patient's wife }\end{array}$ & 5 \\
\hline Housing problems & $\begin{array}{l}\text { Ex 1: Patient and husband live in cramped flat shared } \\
\text { by mother-in-law. Little privacy. No washing machine }\end{array}$ & 2 \\
\hline Severe financial problems & $\begin{array}{l}\text { Patient works long hours without vacation to support } \\
\text { husband and unemployed daughter. Every month } \\
\text { has trouble making ends meet }\end{array}$ & 1 \\
\hline Other crises or misadventures & $\begin{array}{l}\text { Ex 1: Patient mugged while walking in neighbourhood. } \\
\text { Sustains minor injuries, loses purse with papers and } \\
20 \text { pounds, feels unsafe in neighbourhood } \\
\text { Ex 2: Driving from party patient is breathylised; } \\
\text { later fined and loses licence for } 1 \text { year } \\
\text { (needed for sales job) }\end{array}$ & 3 \\
\hline
\end{tabular}

*Marked adversity includes threatening events and/or marked difficulties (see Method).

controls sufficiently thoroughly; further, the period of retrospective distortion and forgetting was much longer in Pratt's study since his typical patient was already moderately disabled.

Since the design of our study was also retrospective, it may be legitimate to question whether vagaries in recall or "effort after meaning" (that is, patients trying to make sense of their symptoms and trying to find reasons for them) might be confounding factors here. With respect to the problem of forgetting, we feel that our study, albeit retrospective, does represent a distinctive step forward through its use of a well validated and reliable life events method-the LEDS. The comprehensive and systemic probing of life circumstances by a trained interviewer makes it less likely that important happenings will be forgotten. At the same time, the method of contextual rating by the investigative team tends to protect the study against inclusion of trivial or idiosyncratically inflated events and diffculties. The exclusion of illness-related events and difficulties attempts to avoid the sort of circularity that sometimes plagues other life events research-for instance, Warren et al.'s ${ }^{14}$ inclusion of "personal illness/injury" as one of the categories of life events inventoried can raise questions about what came first-the illness or the event?
We believe that our focus on patients with relativels recent onset of disease is another strength. Oub patients were individuals who, by and larget experienced their first major symptoms in the preceding 2 to 3 years. This is a much shorter period for which recall has been attempted than has been true for most other studies. Finally, the fact that a longitudinal analysis of our data suggests an upswing in severely threatening life events in the 6 months prior to onset, while rates remained comparable to controls in an earlier 6 month epoch, suggests that patients were not simply overreporting. This inference is strengthened by the finding that there were no significant differences in less threatening events and less severe difficulties between patients and controls.

While our study indicates a temporal relationship between marked adversity and multiple sclerosis symptoms, we cannot prove that this relationship is causal. Recent neuroimmunological research does provide evidence, however, that stress can induce alterations in immune status. ${ }^{29}$ There is also good evidence for the existence of immunological abnormalities in multiple sclerosis, and that they are important pathogenetically. ${ }^{30}$ Since the precise way in which the immunological defect in multiple sclerosis leads to tissue damage is uncertain, it is impossible to 
predict how further alterations induced by stress could initiate or reactivate the disease process. These difficulties notwithstanding, our data, taken with those from other recent investigations, provide evidence for the view that there is a connection between stressful life events and the onset of symptoms or relapse in multiple sclerosis.

Suport for this work was provided by the Medical Research Service of the Veterans Administration and by the Foundations Fund for Research in Psychiatry. The authors are indebted to Dr P C Gautier-Smith, for his enthusiastic support of this study, and particularly, his willingness to identify patients who might be suitable as research subjects. Professors John Marshall and $\mathrm{P} K$ Thomas were also helpful in allowing us access to patients, as were Drs. R W Ross Russell, J A Morgan-Hughes, P Rudge, A N Gale, R Clifford Jones, A J Lees, $P$ Bradbury, and E Byrne. Ms. Marge Zeitsman assisted in scheduling some of our patients. The authors are grateful to Michelle Page for preparing the manuscript.

\section{References}

1 Firth D. The Case of Augustus d'Este. Cambridge: Cambridge University Press, 1948.

2 Charcot JM. Lectures on the Diseases of the Nervous System Delivered at La Salpêtrière, London, New Sydenham Society 1877, Trans., G. Sigerson, lecture delivered 1868.

3 Moxon W. Case of insular sclerosis of brain and spinal cord. Lancet 1873;236.

4 Jelliffe SE. Multiple sclerosis and psychoanalysis. Am J Med Sci 1921;161:666-75.

5 Langworthy OR, Kolb LC, Androp S. Disturbances of behavior in patients with disseminated sclerosis. Am J Psychiatry 1941; 98:243-9.

6 Langworthy OR. Relation of personality problems to onset and progress of multiple sclerosis. Arch Neurol Psychiatry 1948; 59:13-28.

7 Langworthy OR. A survey of the maladjustment problems in multiple sclerosis and the possibilities of psychotherapy. Proceedings of the Association for Research in Nervous and Mental Diseases 1950;28:598-611.

8 Braceland FJ, Giffin ME. The mental changes associated with multiple sclerosis (An interim report). Proceedings of the Association for Research in Nervous and Mental Diseases 1950;28:450-5.

9 Grinker RR, Ham GC, Robbins FP. Some psychodynamic factors in multiple sclerosis. Proceedings of the Association for Research in Nervous and Mental Diseases 1950;28:456-60.

10 Philippopoulos GS, Wittkower ED, Cousineau A. The etiologic significance of emotional factors in onset and exacerbations of multiple sclerosis. Psychosom Med 1958;20:458-74.

11 Mei-Tal V, Meyerowitz S, Engel GL. The role of psychological process in a somatic disorder: multiple sclerosis. Psychosom Med 1970;32:67-86.

12 Pratt RTC. An investigation of the psychiatric aspects of disseminated sclerosis. J Neurol Neurosurg Psychiatry 1951;14:326-36.

13 Antonovsky A, Leibowitz U, Medalie JM, Smith HA, Halpern L, Alter M. Reappraisal of possible etiologic factors in multiple sclerosis. Am J Pub Health 1968;58:836-48.

14 Warren S, Greenhill S, Warren KG. Emotional stress and the development of multiple sclerosis: case-control evidence of a relationship. J Chronic Dis 1982;35:821-31.

15 Franklin GM, Nelson LM, Heaton RK, Burks JS, Thompson DS. Stress and its relationship to acute exacerbations in multiple sclerosis. J Neurol Rehab 1988;2:7-11.

16 Grant I, McDonald WI, Trimble MR, Smith E, Reed R. Deficient learning and memory in early and middle phases of multiple sclerosis. J Neurol Neurosurg Psychiatry 1984;47:250-5.

17 Goldthorpe JH, Hope K. The Social Grading of Occupations: A New Approach and Scale, London: Oxford University Press, 1974.

18 Poser CM, Paty DW, Scheinberg L, et al. New diagnostic criteria for multiple sclerosis: guidelines for research protocols. Ann Neurol 1983;13:227-36.

19 Brown GW, Harris T. Social Origins of Depression: A Study of Psychiatric Disorders in Women, London: Tavistock, 1978.

20 Grant I, Yager J, Sweetwood HL, Olshen R. Life events and symptoms. Fourier analysis of time series from a three-year prospective inquiry. Arch Gen Psychiatry 1982;39:598-605.

21 Grant I, Patterson TL, Olshen R, Yager J. Life events do not predict symptoms: symptoms predict symptoms. J Behav Med 1987;10:231-41.

22 Nielson E, Brown GW, Marmot M. Myocardial infarction. In Brown GW, Harris TO eds. Life Events and Illness, New York: Guilford Press, 1988.

23 Brown GW. Meaning, measurement, and stress of life events. In Dohrewend BS, Dohrewend BP, eds. Stressful Life Events: Their Nature and Effects, New York: Wiley, 1974.

24 Brown GW. Life events and measurement. In: Brown GW, Harris TO, eds. Life Events and Illness, New York: Guilford Press, 1988.

25 Brown GW, Birley J. Crises and life changes and the onset of schizophrenia. J Health Soc Behav 1968;9:203-14.

26 Craig TKL, Brown GW. Goal frustration and life events in the aetiology of painful gastrointestinal disorder. In: Brown GW, Harris TO, eds. Life Events and Illness, New York: Guilford Press, 1988.

27 Creed F. Life events and appendicectomy. Lancet 1981;1:381-5.

28 Harris TO. Disorders of menstruation. In: Brown GW, Harris TO, eds. Life Events and Illness, New York: Guilford Press, 1988.

29 Calabrese JR, Kling MA, Gold PW. Alterations in immunocompetence during stress, bereavement, and depression: focus on neuroendocrine regulation. Am $J$ Psychiatry 1987;144: 1123-34.

30 Lightman A, McDonald WI, Bird AC, Francis DA, Hoskins A, Batchelor JR, Halliday AM. Retinal venous sheathing in optic neuritis: Its significance for the pathogenesis of multiple sclerosis. Brain 1987;110:405-14. 